\title{
Artikel
}

\section{De in- en uitsluitingsclausule in het nieuwe huwelijksvermogensrecht}

\author{
Mr. L.A.G.M. van der Geld*
}

\section{Inleiding}

Op 1 januari 2018 treedt de Wet beperking gemeenschap van goederen in werking. ${ }^{1}$ De beperking van de gemeenschap van goederen zit onder meer in het van rechtswege buiten de gemeenschap vallen van verkrijgingen krachtens erfrecht. Heeft hiermee de uitsluitingsclausule zijn beste tijd gehad? In artikel 1:94 lid 3 onder b van het Burgerlijk Wetboek (BW) (nieuw) is een nieuwe uiterste wilsbeschikking opgenomen: de insluitingsclausule. In deze bijdrage gaat ik in op de inen uitsluitingsclausule in de door het nieuwe huwelijksvermogensrecht veranderende testamentenpraktijk.

\section{De beperking van de gemeenschap}

De kern van de wet houdt een beperking in van de wettelijke gemeenschap van goederen zoals we die nu kennen. In het kort is die beperking dat het voorhuwelijkse niet-gezamenlijke vermogen van ieder van de echtgenoten buiten de gemeenschap van goederen blijft evenals de verkrijgingen krachtens erfrecht en gift (ongeacht of deze vóór of tijdens het huwelijk worden verkregen). In artikel 1:94 lid 2 BW (nieuw) staat daarover onder meer:

'De gemeenschap omvat, wat haar baten betreft, alle goederen die reeds vóór de aanvang van de gemeenschap aan de echtgenoten gezamenlijk toebehoorden, en alle overige goederen van de echtgenoten, door ieder van hen afzonderlijk of door hen tezamen vanaf de aanvang van de gemeenschap, tot haar ontbinding verkregen, met uitzondering van:

a. krachtens erfopvolging bij versterf, making, lastbevoordeling of gift verkregen goederen.' ${ }^{2}$

In lid 6 van artikel 1:94 BW (nieuw) is geregeld dat de vruchten van goederen die niet in de gemeenschap vallen, ook buiten de gemeenschap van goederen vallen.

Volgens de initiatiefnemers is de wettelijke gemeenschap van goederen nu te willekeurig ten aanzien van de verdeling van verkrijgingen krachtens erfrecht. Degene die verkrijgt tijdens het huwelijk zonder uitsluitingsclausule moet die verkrijging wel bij een echtscheiding delen, terwijl de echtgenoot die net ná de echtscheiding krachtens erfrecht verkrijgt die verkrijging niet hoeft te delen. Ook is er sprake van willekeur als de ene echtgenoot tijdens het huwelijk een schenking verkrijgt met een uitsluitingsclausule en de andere echtgenoot een schenking zonder uitsluitingsclausule. ${ }^{3}$

2. In art. 1:94 lid 2 onder c BW (nieuw) is geregeld dat 'rechten op het vestigen van vruchtgebruik als bedoeld in de artikelen 29 en 30 van Boek 4, vruchtgebruik dat op grond van die bepalingen is gevestigd, alsmede hetgeen wordt verkregen ingevolge de artikelen 34, 35, 36, 38, 63 tot en met 92 en 126, eerste en tweede lid onderdelen a en c van Boek 4' buiten de gemeenschap blijven.

3. Kamerstukken I 2016/17, 33987, voortzetting behandeling 21 maart 2017, item 10. 


\section{Uitsluitingsclausule passé?}

Door de beperking van de gemeenschap ten aanzien van erfrechtelijke verkrijgingen stelt menigeen dat de uitsluitingsclausule als uiterste wilsbeschikking niet meer opgenomen wordt in testamenten. Er zijn echter nog steeds redenen om nu (anticiperend op de beperking van de gemeenschap van goederen) en ná 1 januari 2018 uitsluitingsclausules in testamenten op te blijven nemen. Het wordt in elk geval gefaciliteerd door lid 4 van artikel 1:94 BW (nieuw):

'Goederen, alsmede de vruchten van die goederen, ten aanzien waarvan bij uiterste wilsbeschikking of bij de gift is bepaald dat zij buiten de gemeenschap vallen, blijven buiten de gemeenschap, ook al zijn echtgenoten bij huwelijkse voorwaarden overeengekomen dat krachtens erfopvolging bij versterf, making, lastbevoordeling of gift verkregen goederen dan wel de vruchten daarvan in de gemeenschap vallen. ${ }^{4}$

Op grond van lid 4 van artikel 1:94 BW (nieuw) 'dwingt' (naar HR 21 november 1980, NJ 1981/193) en overrulet de uitsluitingsclausule dus de huwelijkse voorwaarde waarin echtgenoten overeenkomen dat erfrechtelijke verkriigingen in de gemeenschap van goederen vallen. Onder degenen die stellen dat de uitsluitingsclausule niet vaak meer in de praktijk gaat voorkomen, zijn de initiatiefnemers. In reactie op het door Huijgen ${ }^{5}$ gestelde dat het nog steeds wenselijk is uitsluitingsclausules op te nemen, reageren zij als volgt:

'Slechts wanneer de erflater of schenker aan de echtgenoten de mogelijkheid wil ontnemen om dergelijke verkrijgingen bij huwelijkse voorwaarden in de gemeenschap te laten vallen of in een verrekenbeding te betrekken, bestaat noodzaak tot een uitsluitingsclausule. (...) het dwingend opleggen van de uitsluitingsclausule zal naar de initiatiefnemers vermoeden niet heel frequent voorkomen. ${ }^{6}$

De leden van de SGP-fractie vragen de initiatiefnemers of de praktijk van het opnemen van uitsluitingsclausules

4. A.L.G.A. Stille, (On)gemene vruchten en de uitsluitingsclausule, WPNR $2005 / 6618$, concludeerde dat er een probleem is ten aanzien van buiten de gemeenschap van goederen te houden vruchten. Met deze bepaling wordt het door Stille geconstateerde probleem opgelost.

5. W.G. Huijgen, De nieuwe beperkte gemeenschap van goederen: nog meer problemen gesignaleerd, FTV 2015/4. Huijgen verzet zich tegen het argument dat vóór de beperking van de gemeenschap is gebruikt, namelijk dat er geen uitsluitingsclausules meer gemaakt zouden hoeven te worden. 'Een testateur of schenker die wil bereiken dat de testamentaire making of gift nimmer in enige gemeenschap van goederen zal vallen en nooit zal worden verrekend krachtens enig verrekenbeding in huwelijkse voorwaarden zal echter nog steeds een uitsluitingsclausule moeten opnemen in de uiterste wilsbeschikking dan wel bij de gift.'

6. Op vragen of er nog steeds uitsluitingsclausules gemaakt worden, antwoordden de initiatiefnemers: 'Slechts wanneer de erflater of schenker aan de echtgenoten de mogelijkheid wil ontnemen om dergelijke verkrijgingen bij huwelijkse voorwaarden in de gemeenschap te laten vallen of in een verrekenbeding te betrekken, bestaat noodzaak tot een uitsluitingsclausule.' Kamerstukken II 2014/15, 33987, 10, p. 4. onder het huidige huwelijksvermogensrecht niet vooral komt uit het gebruik van modellen waar mensen niet bewust voor kiezen, hoewel afwijking ervan wel mogelijk is. Volgens de initiatiefnemers is er geen anleiding te veronderstellen dat er dergelijke onbewuste sturing plaatsheeft, omdat de notaris een actieve zorgplicht heeft. $^{7}$

De uitsluitingsclausule behoudt nog een andere functie onder het nieuwe huwelijksvermogensrecht, namelijk ten aanzien van verkrijgers die vóór 1 januari 2018 in de wettelijke gemeenschap van goederen huwden. In de overgangsbepaling van het wetsvoorstel is namelijk in artikel IV lid 1 bepaald:

'Op een gemeenschap van goederen, ontstaan vóór het tijdstip van inwerkingtreding van deze wet, blijft artikel 94 van Boek 1 van het Burgerlijk Wetboek van toepassing, zoals dat artikel luidde op de dag voorafgaand aan de inwerkingtreding van deze wet. ${ }^{8}$

Daarnaast: een uitsluitingsclausule ziet niet alleen op in gemeenschap van goederen gehuwde verkrijgers, maar ook op verkrijgers die in hun huwelijkse voorwaarden erfrechtelijke verkrijgingen in een verrekenbeding hebben betrokken. Artikel 1:134 BW blijft ongewijzigd; er is in het wetsvoorstel geen 'spiegelbeeldbepaling' voorzien voor huwelijkse voorwaarden.

Verstappen vraagt zich af of het nieuwe huwelijksvermogensrecht niet een andere gedachte ten aanzien van de uitsluitingsclausule met zich brengt:

'Het beste is misschien het al dan niet in de gemeenschap vallen of het al dan niet in de verrekening betrekken gewoon aan de kinderen met hun partner over te laten. ${ }^{9}$

Ik onderschrijf dat de uitsluitingsclausule 'getalsmatig' naar verloop van tijd aan belang inboet. De kans dat echtgenoten na 1 januari 2018 een algehele gemeenschap van goederen overeenkomen bij het aangaan van het huwelijk, acht ik niet groot. Mogelijk gaan we in de toekomst wel zien dat echtgenoten vanwege estateplanningtechnische redenen tijdens het huwelijk (of op het sterfbed) ervoor kiezen huwelijkse voorwaarden te maken inhoudelijk overeenkomend met de algehele gemeenschap van goederen zoals voor 1 januari 2018 was opgenomen in artikel 1:94 BW. Daarnaast 'sterft' de groep verkrijgers die vóór 1 januari 2018 in gemeenschap van goederen huwde ook een keer uit. Voor de verkrijger die op huwelijkse voorwaarden gehuwd is en in de toekomst huwt, blijft de uitsluitingsclausule onverminderd van belang (vanwege het hiervoor genoemde art. 1:134 BW, dat ongewijzigd blijft). Mogelijk neemt na 1 januari 2018 het aantal echtparen dat huwelijkse voorwaarden

\footnotetext{
Kamerstukken II 2014/15, 33987, 10, p. 15

Kamerstukken II 2014/15, 33987, 5, p. 4.

L.C.A. Verstappen, Wetsvoorstel beperking gemeenschap van goederen aangenomen!, WPNR 2017/7146.
} 
overeenkomt af, al zijn er nog voldoende redenen voor huwelijkse voorwaarden te kiezen. ${ }^{10}$

Mijn verwachting is dat in de testamentenmodellen nu en in de toekomst nog steeds de uitsluitingsclausule prijkt. Notarissen adviseren over het algemeen om alles zo veel mogelijk 'dicht te zetten': met een uitsluitingsclausule wordt voorkomen dat de verkrijging in een bij huwelijkse voorwaarden overeengekomen 'algehele gemeenschap' valt. Daarbij komt dat de verkrijger reeds vóór 2018 in het huwelijk getreden kan zijn of op huwelijkse voorwaarden met een verrekenbeding waarin erfrechtelijke verkrijgingen worden betrokken. De uitsluitingsclausule krijgt wel een andere formulering, rekening houdend met verkrijgers ten aanzien van wie de beperkte gemeenschap van goederen geldt en de erfrechtelijke verkrijgingen van rechtswege buiten de gemeenschap van goederen vallen (zie ook hierna par. 5). Mogelijk zijn er principiële testateurs die menen dat als de verkrijger de moeite heeft genomen huwelijkse voorwaarden te maken en daarin heeft gekozen om erfrechtelijke verkrijgingen in de gemeenschap van goederen te laten vallen, de uitsluitingsclausule niet moet dwingen. De praktijk zal het uitwijzen.

\section{Nieuw: de insluitingsclausule}

In lid 3 onder b van artikel 1:94 BW (nieuw) wordt de insluitingsclausule in het huwelijksvermogensrecht geïntroduceerd. Een erfrechtelijke verkrijging blijft niet buiten de gemeenschap van goederen als in een uiterste wilsbeschikking is bepaald dat deze in de gemeenschap valt.

Ten aanzien van de insluitingsclausule is niet een bepaling als in lid 4 van artikel 1:94 BW (nieuw) opgenomen; de insluitingsclausule dwingt dus niet als de echtgenoten anders zijn overeengekomen in huwelijkse voorwaarden. Ondanks het bepaalde in lid 4 behoudt een testateur overigens de vrijheid in de uitsluitingsclausule op te nemen dat de vruchten van de erfrechtelijke verkrijging wel in de gemeenschap van goederen vallen. ${ }^{11}$

De insluitingsclausule kan in het kader van estateplanning wenselijk zijn. De insluitingsclausule is in huidige termen de 'nuancering of verzachting' op de uitsluitingsclausule, de voorwaardelijke uitsluitingsclausule. Er zijn testateurs die niet slechts een 'harde uitsluitingsclausule' in hun testament willen opnemen: bij ontbinding van het huwelijk van de verkrijger door overlijden vindt de testateur het voornamelijk vanuit successie-

10. Bijv. voor ondernemers, zie ook T.J. Mellema-Kranenburg, Maakt wetsvoorstel 33987 huwelijkse voorwaarden overbodig of juist noodzakelijk?, WPNR 2015/7054

11. Kamerstukken II 2013/14, 33987, 3, p. 16. rechtelijk perspectief wenselijk dat de erfrechtelijke verkrijging wordt verrekend. ${ }^{12}$

De initiatiefnemers kozen voor de insluitingsclausule omdat er in het huidige recht op grote schaal voor voorwaardelijke uitsluitingsclausules wordt gekozen. ${ }^{13}$ De initiatiefnemers menen dat de in- en uitsluitingsclausule een 'goederenrechtelijke' werking kunnen hebben omdat er bij het opnemen van een in- of uitsluitingsclausule geen sprake van een voorwaardelijke huwelijksgemeenschap is, aangezien de verkrijging voorwaardelijk is en niet de huwelijksgemeenschap. ${ }^{14} \mathrm{Zij}$ verwijzen daarbij naar voorwaardelijke verkrijgingen zoals artikel 3:38, 3:84, 3:91 e.v. BW en naar de tweetrapsmakingen in Boek 4 BW. 'Er bestaan geen wettelijke aanknopingspunten noch inhoudelijke redenen om hierop voor de toepassing van in- en uitsluitingsclausules een uitzondering te maken', schrijven de initiatiefnemers aan het einde van hun pleidooi. In de literatuur is uitgebreid gediscussieerd over de vraag of een voorwaardelijke uitsluitingsclausule in goederenrechtelijke zin mogelijk is vanuit de veronderstelling dat de huwelijksvermogensrechtelijke gemeenschap onvoorwaardelijk moet zijn. ${ }^{15}$

Met de opmerkingen uit de parlementaire geschiedenis lijkt de discussie definitief ten einde. Recent plaatste Vegter echter vraagtekens bij de stelling van de initiatiefnemers dat voorwaardelijke in- en uitsluitingsclausules mogelijk zijn, en komt tot de volgende conclusie:

'Zolang voorwaardelijk werkende huwelijksvermogensregimes in strijd zijn met de wet, is een voorwaardelijk werkende uitsluitingsclausule of een voorwaardelijk werkende insluitingsclausule met diezelfde wet in strijd.' 16

Bossers en Schols stelden vorig jaar in hetzelfde tijdschrift dat voortaan (overigens niet vanwege het wetsvoorstel beperking gemeenschap van goederen) een opschortende voorwaarde kan worden verbonden aan de gemeenschap van goederen. ${ }^{17}$ In deze visie is de onmogelijkheid van een voorwaardelijke huwelijksvermogensrechtelijke gemeenschap van goederen inmiddels achterhaald.

12. Er worden in sommige gevallen voorwaarden aan verbonden, zoals dat het moet gaan om ontbinding van het huwelijk door het overlijden van de verkrijger en er moeten één of meer afstammelingen in leven zijn.

13. Kamerstukken I 2016/17, 33987, C, p. 27.

14. Kamerstukken I 2016/17, 33987, C, p. 28.

15. De discussies leidden onder meer tot de volgende publicaties: C.A. Kraan, De voorwaardelijke uitsluitingsclausule, WPNR 1995/6177; M.J.A. van Mourik, Reikwijdte uitsluitingsclausule, WPNR 1993/6075; W.M. Kleyn, Een geclausuleerde uitsluitingsclausule, JBN (87) 1996, afl. 10; W.R. Meijer, De uitsluitingsclausule, standaard met variaties, WPNR 1996/6235; J.B. Vegter, Over het eenheidsbeginsel in het huwelijksvermogensrecht en over flexibilisering van de uitsluitingsclausule, WPNR 2010/6826.

16. J.B. Vegter, Over voorwaardelijk werkende goederenrechtelijke huwelijksvermogensregimes en in- of uitsluitingsclausules, WPNR $2017 / 7154$.

17. J. Bossers-Cnossen \& B.M.E.M. Schols, Het zo veranderlijke, voorwaardelijke huwelijksgoederenregime, WPNR 2016/7090 en 7091 


\section{De redactie van de in- en uitsluitingsclausule}

Het is tijd om naar de formulering van de uitsluitingsclausules te kijken en een tekst voor de insluitingsclausule te maken. Zoals hiervoor anngegeven, wijzigt de functie van de uitsluitingsclausule enigszins; hiermee rekening houdend kom ik dan tot de volgende suggestie voor de vormgeving van de uitsluitingsclausule:

- De erfrechtelijke verkrijging valt niet in enige huwelijksvermogensrechtelijke gemeenschap (hiermee wordt verwezen naar de huidige wettelijke gemeenschap en de bij huwelijkse voorwaarden overeengekomen gemeenschap waarin erfrechtelijke verkrijgingen vallen).

- De erfrechtelijke verkrijging wordt niet betrokken in een bij huwelijkse voorwaarden overeengekomen verrekenbeding.

Daarbij wordt aangegeven of ook de vruchten buiten de gemeenschap (in goederenrechtelijke zin) en buiten de verrekening blijven.

De insluitingsclausule zal vooral worden gebruikt om de uitsluitingsclausule in oude begrippen te verzachten. ${ }^{18}$ In nieuwe termen smelten de uitsluitingsclausule en de insluitingsclausule als volgt samen:

- De uitsluitingsclausule geldt voor het geval het huwelijk van de verkriiger eindigt door echtscheiding.

- De insluitingsclausule geldt voor het geval het huwelijk van de verkrijger eindigt door overlijden.

Hiermee krijgt de verkrijging een voorwaardelijk karakter, hetgeen volgens de parlementaire geschiedenis geen probleem is. ${ }^{19}$ Er kunnen overigens aan de insluitingsclausule nog nadere voorwaarden worden verbonden, zoals dat het huwelijk door overlijden van de verkrijger is ontbonden en/of er kinderen uit het huwelijk zijn geboren.

Reijnen draagt als alternatief voor de insluitingsclausule de benoeming (in de situatie dat de testateur kinderen heeft) van het in beperkte gemeenschap gehuwde kind en diens echtgenoot tot erfgenaam, ieder voor de helft. ${ }^{20}$ Aan de erfstelling van het schoonkind wordt de voorwaarde verbonden dat het huwelijk niet door echtscheiding is ontbonden en andere voorwaarden die ook aan een voorwaardelijke uitsluitingsclausule plegen te worden verbonden.
Als er opnieuw an de modeltekst van de uitsluitingsclausule gesleuteld gaat worden, dan is het goed te bedenken dat het nauw luistert met de tekst van deze clausule. Dat bleek onlangs uit een uitspraak van het Hof Arnhem-Leeuwarden. ${ }^{21}$ In deze zaak was de vraag wat de reikwijdte was van de uitsluitingsclausule in het testament van erflater, die luidde:

'Tenslotte bepaal ik dat al hetgeen mijn kinderen eventueel uit mijn nalatenschap zullen erven niet zal vallen in enige gemeenschap van goederen waarin zij ten tijde van mijn overlijden mochten zijn gehuwd (...)'

De vraag was of deze clausule ook werkt nu de verkrijger na het overlijden van erflater zonder huwelijkse voorwaarden in het huwelijk trad. Volgens het hof moet zo dicht mogelijk bij de letterlijke tekst van de uitsluitingsclausule worden gebleven, omdat de bedoeling van de erflater dat de uitsluitingsclausule ook voor een huwelijk na zijn overlijden geldt, niet inzichtelijk is geworden. Het hof gaat ervan uit dat erflater aan zijn kinderen de keuze en verantwoordelijkheid heeft gelaten of zijn vermogen na zijn overlijden in enige gemeenschap zou vallen.

Hier is less is more wellicht het beste devies: waarom laten we frases als 'waarin zij ten tijde van het overlijden mochten zijn gehuwd' of 'waarin de verkrijger nu of in de toekomst gaat trouwen' niet gewoon weg?

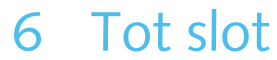

De uitsluitingsclausule neemt wellicht enigszins in betekenis af, maar blijft naar mijn verwachting een onderdeel van testamenten. Er is een functie bij huwelijken van verkrijgers gesloten vóór de inwerkingtredingsdatum van 1 januari 2018 van het nieuwe huwelijksvermogensrecht en bij de verkrijgers die in de huwelijkse voorwaarden hebben opgenomen erfrechtelijke verkrijgingen te verdelen of te verrekenen. De uitsluitingsclausule wordt versmolten met de insluitingsclausule als het gaat om testateurs wens om een voorwaardelijke (goederenrechtelijke) uitsluitingsclausule op te nemen. Mede gezien de voormelde uitspraak van het Hof ArnhemLeeuwarden is het scherp formuleren van de in- en uitsluitingsclausule van groot belang.
18. Het huwelijksvermogensregime van de verkrijger zal de insluitingsclausule wel moeten kunnen 'dragen', anders heeft de insluitingsclausule geen effect, nu deze niet dwingend is zoals de uitsluitingsclausule.

19. Gezien de discussie over de goederenrechtelijke werking zou nog veiligheidshalve voor het overnemen van de letterlijke wettekst van de insluitingsclausule kunnen worden gekozen.

20. T.F.H. Reijnen, De nieuwe gemeenschap van goederen, FBN (12) 2016, afl. 3 . 